\title{
Advancing Patient Safety Surrounding Medical Devices: A Health System Roadmap to Implement Unique Device Identification at the Point of Care
}

\author{
Natalia A Wilson (D) \\ James $E$ Tcheng $\mathbb{D}^{2}$ \\ Jove Graham ${ }^{3}$ \\ Joseph P Drozda Jr $\mathbb{D}^{4}$ \\ 'College of Health Solutions, Arizona \\ State University, Phoenix, AZ, USA; \\ ${ }^{2}$ Duke University School of Medicine and \\ Health System, Durham, NC, USA; \\ ${ }^{3}$ Center for Pharmacy Innovation and \\ Outcomes, Geisinger, Danville, PA, USA; \\ ${ }^{4}$ Outcomes Research, Mercy, \\ Chesterfield, MO, USA
}

Correspondence: Natalia A Wilson College of Health Solutions, Arizona State University, 500 N. 3rd St., Phoenix, AZ, 85004, USA

Email natalia.wilson@asu.edu
Background: The US Food and Drug Administration's Unique Device Identification System Rule of 2013 mandated manufacturers to assign unique device identifiers (UDIs) to their medical devices. Most high-risk (Class III), moderate-risk (Class II) and implantable devices now have UDIs. To achieve the necessary next step for a comprehensive UDIenabled system for patient safety, UDIs must be electronically documented during patient care, a process not routinely done. The purpose of this research was to study the implementation experiences of diverse health systems in order to develop a roadmap for UDI implementation at the point of care.

Methods: Semi-structured interviews were conducted with personnel at health systems that had implemented UDI for implantable devices in their cardiac catheterization labs or operating rooms. Interviews were audio-recorded, transcribed, and analyzed using the framework methodology of Ritchie and Spencer. Data interpretation involved development of a conceptual model and detailed recommendations for UDI implementation. An expert panel evaluated and provided input on the roadmap.

Results: Twenty-four interviews at ten health systems were conducted by phone. Participants described implementation steps, factors and barriers impacting implementation. Findings populated a UDI implementation roadmap, that includes Foundational Themes, Key Components, Key Steps, UDI Use, and Outcomes.

Conclusions and Implications: The UDI implementation roadmap provides a framework for health systems to address the necessary steps and multilevel factors that underpin UDI implementation at the point of care. It is intended to guide and advance routine electronic documentation of UDIs for devices used during clinical care, the critical next step for a comprehensive UDI-enabled system to enhance medical device safety and effectiveness for patients.

Keywords: unique device identifiers, implants, implementation framework, UDI-enabled system, implantable devices

\section{Introduction}

The Unique Device Identification System Rule ${ }^{1}$ of 2013 was a significant regulatory effort by the US Food and Drug Administration (FDA) to advance patient safety surrounding medical devices. The Rule mandated that manufacturers assign unique device identifiers (UDIs) to their medical devices. ${ }^{2}$ A UDI is a unique code that is required on the label and packaging of a medical device in both human and machine-readable forms. The UDI consists of the Device Identifier (DI) which identifies the device manufacturer and model and the Production Identifier (PI) 
which identifies, as available, the lot number, serial number, expiration date, and/or date of manufacture. The UDI must also be directly marked on the device if the device is intended for more than one use and is reprocessed before use. ${ }^{3}$ UDIs are now included in the packaging for most moderate- and high-risk (Class II and III) and implantable devices. $^{3}$

Despite this progress, UDIs on device labels and packaging are alone insufficient to achieve a comprehensive UDI-enabled system for patient safety. UDIs must be routinely scanned and recorded in health information technology (IT) systems during patient care. Once a standard record (the UDI) has been electronically established, ${ }^{4,5}$ these patient-level device data are available, alone or in aggregate, for clinical, safety surveillance, research, and regulatory purposes. ${ }^{6,7}$

Documented UDIs have important clinical uses. UDI availability from a patient's prior procedure supports clinician decision-making before a revision procedure, such as selection of the replacement implant and instrumentation for removal of the failed implant. ${ }^{7,8}$ Including UDIs on implant cards or in patient portals supports patients' longterm safety and engagement in their medical care. ${ }^{9}$ UDI use in recall management adds accuracy, efficiency and effectiveness, supporting patient safety and quality of care. $^{10,11}$

Documented UDIs also have important downstream uses that support patient safety. UDIs in adverse event reports provide precise identification of devices, more complete and accurate records of device performance and the relative frequency of adverse events, all critical to support decision-making about devices that may not be performing well. UDIs in recall notifications support a standard in medical device recall communications. ${ }^{4}$ UDIs transferred from health systems to clinical registries such as the National Breast Implant Registry $(\mathrm{NIBR})^{7,12}$ and the American Joint Replacement Registry (AJRR), ${ }^{13}$ augment tracking trends in device performance to support patient safety and clinical decision-making. UDIs support linkage of clinical and device data for more robust datasets for research on device comparative effectiveness or performance, ${ }^{14}$ a process that currently requires significant data cleansing and manual work.

Whereas some health systems have implemented UDIs in clinical workflows and routinely scan and electronically document UDIs at point of care (POC) sites such as cardiac catheterization labs (cath labs) or operating rooms (ORs), practical recommendations and guidance for UDI implementation in health systems are limited. This leaves an information gap necessary to advance UDI adoption. Additionally, the absence of policy requiring health systems to use UDIs has contributed to slow progress. ${ }^{7,11,14-17}$ Both of these factors are significant impediments to achieving the goal of a comprehensive UDI-enabled system for patient safety.

The objective of the reported study was to understand the experiences of health systems that had implemented UDI at the POC in order to develop a set of practical recommendations for health system implementation, building on prior work $^{18-20}$ and advancing the field. Implantable devices were the focus because they are higher risk, discussion of all devices would impact the level of detail possible in interviews, and a roadmap for higher risk devices could serve as a model for broad UDI implementation.

\section{Methods}

Setting and study oversight: This project, based at Arizona State University, was part of Building UDI into Longitudinal Data for Medical Device Evaluation (BUILD) ${ }^{14}$ The project included creation of a multistakeholder consortium of acknowledged UDI leaders from health systems, manufacturers, the federal government, patient and industry advocacy groups (BUILD Consortium $)^{21}$ and study of the experiences of health systems in implementing UDI at the POC.

Data collection: Semi-structured interviews were conducted between June and November 2018 with personnel in health systems that had implemented UDI for implantable devices in cath labs or the OR. Health system selection was guided by the BUILD Consortium. A contact at each system confirmed implementation status, willingness to participate, and identified potential interviewees from supply chain management, POC sites, and IT. Potential interviewees received an invitation email.

Prior to interviews, each health system completed a brief online survey (Qualtrics, Provo, UT) to obtain demographics, IT system characteristics and basic UDI information. Interviewees were orally consented prior to the interviews, which were conducted by phone by a research team member experienced in qualitative research methods. The semi-structured interview guide was informed by the literature on UDI and technology adoption, research team members, and the BUILD Consortium. Topics included the reasons for UDI 
implementation, requisite support and infrastructure, facilitators, barriers, UDI use, and current state. (Interview Guide is available in Supplementary Material.) Interviews were recorded and professionally transcribed. Audio files and transcripts were stored on a secure server.

Data analysis: Survey responses were aggregated and organized using Microsoft Excel. Frequencies were used to describe the sample. Transcripts were analyzed utilizing a multi-step process, guided by the framework methodology of Ritchie and Spencer - familiarization, identifying a thematic framework, indexing, charting, and mapping and interpretation. ${ }^{2-24}$ Transcripts were reviewed in detail for familiarization of content, then reviewed line-by-line to identify codes describing content. Codes were grouped into categories to form an analytic framework, which was applied to transcripts. To verify agreement and establish inter-rater reliability (IRR), ten percent of transcripts were coded by two members of the research team and coding was compared. Coded data were reduced by charting them into Excel to allow comparison across health systems. Data were interpreted through review of the charted data to identify patterns across health systems and how categories were connected. This process was used to develop a conceptual model and recommendations representing a roadmap for UDI implementation.

Expert Panel. Project results and the draft roadmap were presented and discussed during a April 3, 2019 meeting, attended by BUILD Consortium and research team members. Meeting proceedings were recorded and transcribed. BUILD Consortium and research team members received the transcript and an updated roadmap, eliciting input. Input was collected by the research team from eight involved panelists, organized based on topic, and informed draft revisions. Three cycles of iterative revisions were performed on the roadmap.

The study protocol was approved by the Arizona State University Office of Research Integrity and Assurance.

\section{Results}

Twenty-four interviews were conducted in ten participating health systems. The majority were nongovernment, were not-for-profit, included an academic medical center, and offered a health care plan. A range of geographic location, system size, and revenue was represented (Table 1). Interviewees represented executive, director, manager, and clinical positions.

The majority of health systems utilized the same electronic health record (EHR) (Epic Systems, Verona, WI) and one
Table I Demographics of Participating Health Systems

\begin{tabular}{|c|c|c|}
\hline Demographic & $\begin{array}{l}\text { Response } \\
(n=10)\end{array}$ & $\begin{array}{l}\text { Percentage } \\
\text { (\%) }\end{array}$ \\
\hline \multicolumn{3}{|l|}{ Organizational Structure } \\
\hline Nongovernmental, not-for-profit & 9 & 90 \\
\hline Government & I & 10 \\
\hline \multirow{2}{*}{\multicolumn{3}{|c|}{$\begin{array}{l}\text { Academic Medical Center in } \\
\text { System }\end{array}$}} \\
\hline & & \\
\hline Yes & 8 & 80 \\
\hline No & 2 & 20 \\
\hline \multicolumn{3}{|l|}{ Health Care Plan in System } \\
\hline Yes & 8 & 80 \\
\hline No & 2 & 20 \\
\hline \multicolumn{3}{|l|}{ Primary Region in United } \\
\hline \multicolumn{3}{|l|}{ States } \\
\hline South & I & 10 \\
\hline Northeast & 3 & 30 \\
\hline Midwest & 2 & 20 \\
\hline West & 3 & 30 \\
\hline All & I & 10 \\
\hline \multirow{2}{*}{\multicolumn{3}{|c|}{$\begin{array}{l}\text { Number of Hospitals in } \\
\text { System }\end{array}$}} \\
\hline & & \\
\hline$<5$ & 3 & 30 \\
\hline $5-<10$ & 1 & 10 \\
\hline $10-25$ & 3 & 30 \\
\hline$>25-60$ & 2 & 20 \\
\hline$>100$ & 1 & 10 \\
\hline \multicolumn{3}{|l|}{ Revenue in 2017 (billions \$) } \\
\hline $1-<5$ & 3 & 30 \\
\hline $5-15$ & 5 & 50 \\
\hline $16-50$ & 0 & 0 \\
\hline$>50$ & I & 10 \\
\hline N/A & I & 10 \\
\hline
\end{tabular}

of two enterprise resource planning systems (ERP) (Infor/ Lawson, New York, NY or PeopleSoft, Pleasanton, CA). However, there was significant diversity with the POC IT systems where the UDI was documented. Nine systems were represented in the cath lab and six in the OR.

The cath lab was the location where most participating health systems were capturing UDI, followed by the OR, and Interventional Radiology (IR) (Figure 1). Six were capturing UDIs in the cath lab and OR. Five were capturing UDIs in the cath lab, OR, and IR.

The final roadmap resulted from the framework analysis and expert panel work. A conceptual model is presented in Figure 2. Domains are Foundational Themes, Key Components, Key Steps, UDI Use, and Outcomes. 


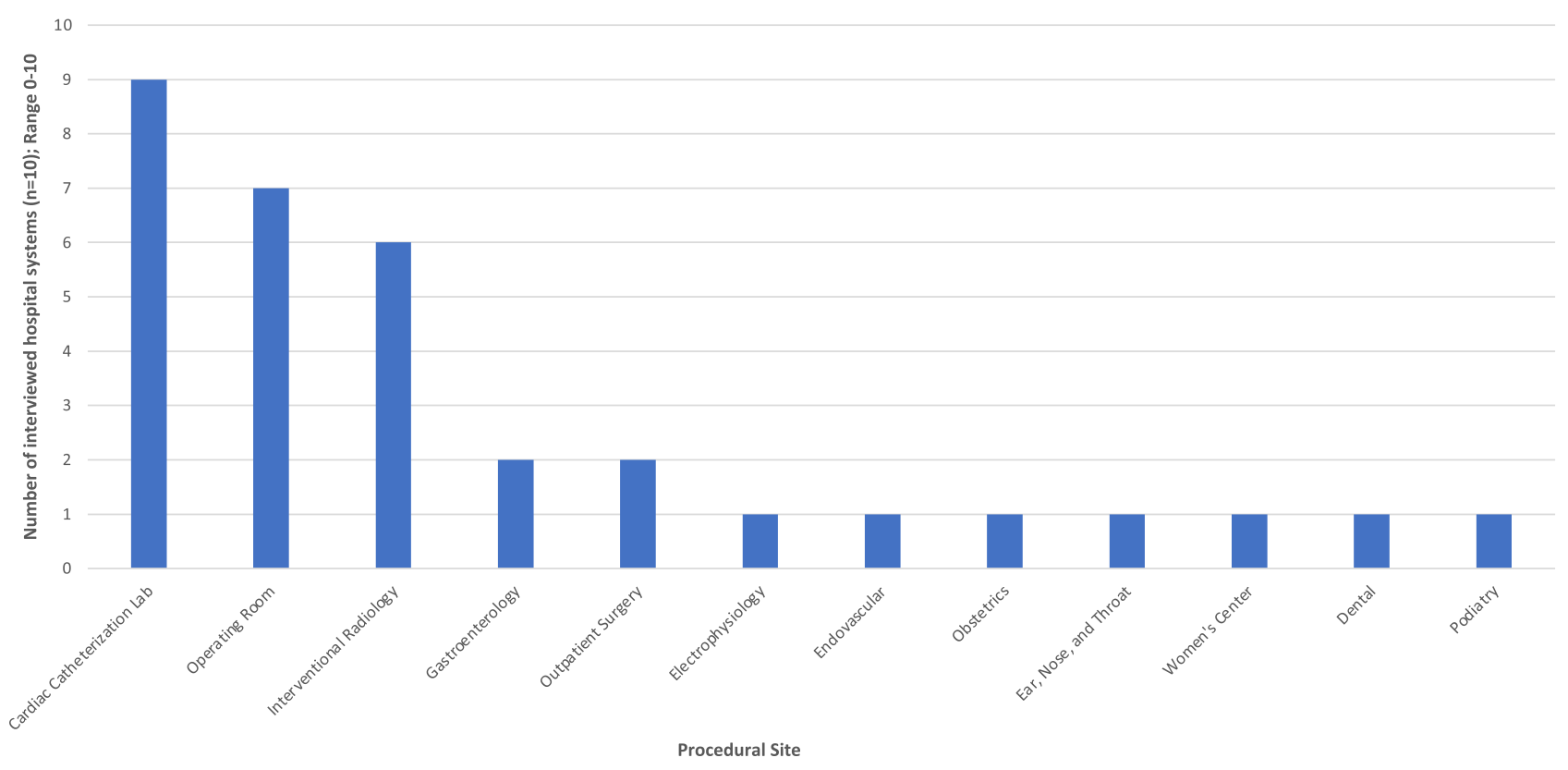

Figure I Sites of unique device identifier (UDI) capture in participating health systems. Identification of procedural sites where UDIs were being captured and number of health systems capturing in these sites are indicated.

\section{Roadmap}

Foundational Themes transcend any one step or component and underpin implementation. Holistic vision is a vision of the value of UDI implementation across health system organizational units. Interprofessionalism represents personnel from different disciplines working together, involving Collaboration, work towards a common goal, and Communication, exchange of information. UDI Implementation involves Data Integrity, collection of valid and accurate UDI data across all

\section{KEY COMPONENTS \& KEY STEPS}

FOUNDATIONAL
THEMES
Holistic Vision
Interprofessionalism
Collaboration
Communication
Data Integrity
Innovation
Resilience

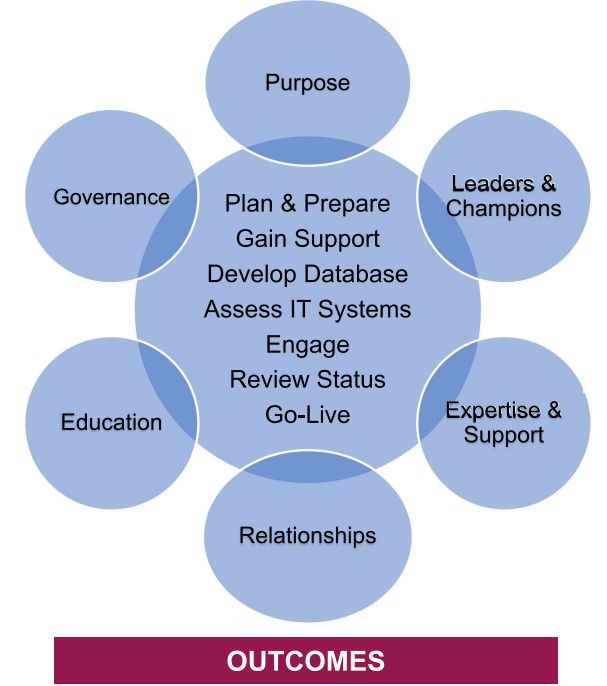

\section{UDI USE}

Clinical

Research

Operational

Enhanced Safety; Clinician Support; Data Visibility; Error Reduction; Operational Efficiency \& Accuracy

Figure $2 \mathrm{~A}$ conceptual model for health systems to implement unique device identification at the point of care. Presented are domains for Implementation of unique device identifiers (UDIs): Foundational Themes, Key Components, Key Steps, UDI Use, and Outcomes.

Abbreviation: IT, information technology. 
touchpoints, as well as Innovation, introducing new methods to facilitate advancement. Resilience is needed to continue progression despite challenges.

Key Components are areas to identify and develop for successful advancement through key steps (Table 2).

Purpose is the reason(s) for UDI implementation. Clinical purpose is to support safe and high-quality patient care through access to accurate and consistent device information. As an interviewee stated: “... Quality and safety aspects will be very much helped by (UDI use)." Research purpose is to support comparative effectiveness and device evaluation. Regulatory purpose is to meet policy requirements such as a future requirement for UDIDIs of high-risk implantable devices in insurance claims. Operational purpose is to foster efficiency, accuracy and to achieve organizational value. Purpose(s) need to be determined early, shared to foster understanding, and remain a focus throughout implementation.

Leaders and Champions are influential individuals who lead by driving goals and/or champion by advocating for UDI implementation. In the clinical arena, this is generally

Table 2 Key Components in UDI Implementation at the Point of Care

\begin{tabular}{|c|c|}
\hline Key Component & Sub-Component \\
\hline Purpose & $\begin{array}{l}\text { - Clinical } \\
\text { - Research } \\
\text { - Regulatory } \\
\text { - Operational }\end{array}$ \\
\hline $\begin{array}{l}\text { Leaders \& } \\
\text { Champions }\end{array}$ & $\begin{array}{l}\text { - Clinical } \\
\text { - Administrative } \\
\text { - Supply Chain Management } \\
\text { - Information Technology } \\
\text { - UDI Initiative Leader }\end{array}$ \\
\hline $\begin{array}{l}\text { Expertise \& } \\
\text { Support }\end{array}$ & $\begin{array}{l}\text { - Supply Chain Management } \\
\text { - Clinical Point of Care } \\
\text { - Information Technology }\end{array}$ \\
\hline Relationships & $\begin{array}{l}\text { - Leadership-Leadership } \\
\text { - Supply Chain Management-Clinical } \\
\text { - Supply Chain Management-Information } \\
\text { Technology } \\
\text { - Supply Chain Management-Manufacturer } \\
\text { - Clinical-Clinical }\end{array}$ \\
\hline Education & $\begin{array}{l}\text { - Self-education } \\
\text { - Education of others }\end{array}$ \\
\hline Governance & $\begin{array}{l}\text { - Informal } \\
\text { - Formal }\end{array}$ \\
\hline
\end{tabular}

a physician or nurse who has cross-disciplinary involvements (supply chain, IT, and/or research) along with clinical duties. Central to success, clinical champions are knowledgeable, committed, and communicate well as they move between organizational silos. In administration, this may be a C-suite hospital leader or a POC director. One interviewee shared:

"Our cath lab director from our largest hospital helped champion the effort and saw the long-term benefit of doing this, then the others ... were very accommodating.“

In supply chain management, this is generally an executive leader who brought the UDI vision to the organization and is the genesis of implementation. IT leaders drive the significant technical build. UDI Implementation leader(s), formal or informal, are "the glue" of the initiative. Leaders and champions are foundational.

Expertise and Support is needed from supply chain management, clinical, and IT arenas. Supply chain management is generally the starting point, involving significant effort, resources, and teams. One interviewee stated: "Supply chain management gets it (the value of UDI)." IT teams are critical to assess IT capabilities, develop, test, and implement changes for the desired infrastructure. POC personnel may be more difficult to engage but are indispensable to inform implementation teams about clinical workflow and champion change at the POC. Expertise and Support are critical aspects of UDI implementation.

Relationships are interdisciplinary, internal and external to the organization. Organizational, supply chain management, and/or clinical leadership relationships are important at the genesis. Supply chain management personnel foster relationships broadly, mobilize supply chain teams, develop interdisciplinary workgroups, work with IT to create the needed infrastructure and with manufacturers to address barriers. Engaged clinicians champion, influence peers, and lead clinical education efforts. Relationships and collaboration toward a common goal cannot be overemphasized. As one interviewee stated: "This is one of the few things that brings everybody together."

Education involves self-education and education of others. Interviewees became educated at conferences, joined interdisciplinary groups ${ }^{16}$, and stayed abreast of research. ${ }^{9,11,14,15,17,25,26}$ As one interviewee stated: "Be a student of data standards." Education of others must be high quality and succinct, convenient, and inclusive of the purpose(s) of UDI implementation. Peer-peer education, especially with clinical staff, is powerful. Education must 
continue for new staff and implementation sites, and to maintain current staff knowledge.

Governance in a formal sense was lacking for many of the participating health systems who were "early adopters" where efforts evolved from a grassroots level. Participating health systems were on a continuum. Some had started UDI implementation quite some time ago where a small informal group drove change. An example of the most formal governance structure, in a health system with more recent implementation, involved a UDI governance committee, implementation leader, charter and timeline, engagement of analysts, and multiple workgroups.

Key Steps constitute the core of UDI implementation (Table 3).

Plan \& Prepare. Purpose(s) is identified. Flow of devices in the health system and areas that may be impacted by UDI implementation are studied. Leaders, champions, needed expertise and support, and ongoing larger projects (eg EHR implementation, supply chain modernization initiatives, research projects) in which UDI implementation may be a part are identified. A pilot site is picked. Five of the participating health systems piloted in the cath lab, because it was more contained, with more limited procedures and implants, had a dedicated staff, and a clinical champion. Governance, leadership, and strategy for implementation is conceptualized. Potential barriers are considered.

Project-identified barriers included clinical resistance, IT gaps and vendor resistance, FDA's Global UDI Database (GUDID) gaps, lack of manufacturer support, lack of organizational support, and limitations for an overall UDI-enabled system (eg policy, evidence base, leadership). Engagement, education, and communication of purpose were important strategies to overcome clinical resistance. Early engagement of IT vendors, evaluation of third-party vendors, and use of internal IT teams were strategies for IT gaps. GUDID gaps were addressed through communication with FDA and engagement in industry workgroups. Communication and contract provisions were used to address manufacturer challenges. Organizational and overall support for a UDI system were addressed through internal and external relationships, policy advocacy, and education.

Gain Support. A focused presentation to those who approve the needed work and provide resources is done. Effort is also focused on obtaining local support. One interviewee shared their message at the POC: "This is what we are going to do. These are the benefits. It is going to be tough adoption at first but long-term it is really going to help."

Develop the Database. Decision on which IT system will house the database that supports UDI scanning at the POC and developing this capability is done. Whereas the ERP item master was the desired location for the database, 3rd party POC IT systems and the clinical documentation system/EHRs were alternative locations. AccessGUDID was generally utilized as a source of external data to support the database, but due to its data limitations, health systems utilized vendor and 3rd party data. Health systems felt that the GUDID had data inaccuracy and errors, gaps, and limitations in terms of attributes submitted and depth/breadth of data.

Assessment of IT Systems. The technical build for UDI implementation is a large component. Comprehensive device data management for the organization unifying IT systems with the UDI needs to be established. IT systems must be able to accept, record, and transmit UDI. As stated by one interviewee, "(There is a) fundamental gap in where to put data and get it out of the system." The ERP system, POC IT systems including clinical documentation/ EHRs and inventory management systems, and barcode scanners need to be assessed for necessary adaptation or change to new systems which may include innovation with an IT vendor to achieve the desired goal. The approach is one that builds an infrastructure for UDI use.

Engage. Engagement with leaders, champions, and staff at POC sites is critical to build relationships in addition to create opportunities for education. As previously mentioned, "Supply chain management gets it, others need convincing." However, also shared, "Everybody understands patient safety." Engagement with IT, internal and/ or external, needs to start early for prioritization and support of the technical build.

Review Status Assessment of readiness of the device database, IT infrastructure, education, and testing to golive is done.

Go-live. On-site and ongoing support particularly for clinical staff and quick responsiveness to changes is needed.

UDI Use, which supports attainment of purpose, was generally not robust. One interviewee stated: "Do not know as have been focused on getting (the system) up and running." Uses shared were documentation in procedure reports and the EHR implant log, in recalls, and inclusion in datasets for clinical comparative research. Another interviewee stated: "(UDI readiness) puts the engine in place to do comparative effectiveness research." 
Table 3 Key Steps in Unique Device Identification Implementation at the Point of Care*

\begin{tabular}{|c|c|}
\hline Key Step & Detailed Steps \\
\hline Plan \& Prepare & $\begin{array}{l}\text { I. Start early (at least six months) } \\
\text { 2. Identify the Purpose } \\
\text { 3. Assess all processes and touchpoints for devices in the organization } \\
\text { 4. Determine units and stakeholders that will be impacted by UDI implementation } \\
\text { 5. Identify ongoing and necessary Relationships } \\
\text { 6. Identify potential Leaders \& Champions } \\
\text { 7. Delineate necessary areas of Expertise \& Support } \\
\text { 8. Determine leadership and Governance of UDI implementation } \\
\text { 9. Pick the pilot site } \\
\text { 10. Delineate potential barriers } \\
\text { II. Conceptualize strategy including Education }\end{array}$ \\
\hline Gain Support & $\begin{array}{l}\text { I. Determine who approves the needed work and provides resources } \\
\text { 2. Deliver a presentation, inclusive of Purpose, data, value and key drivers of UDI implementation, a vision, } \\
\text { outline of a plan } \\
\text { 3. Garner local support with colleagues, impacted stakeholders, Leaders \& Champions }\end{array}$ \\
\hline Develop Database & $\begin{array}{l}\text { 1. Determine the location of your organizational device database needed for POC UDI capture } \\
\text { 2. Assess the current status as well as resources needed and a plan to reach the desired state } \\
\text { 3. Assess data needed to support database accuracy as an organizational source of truth } \\
\text { 4. Work with supply chain and IT partners to develop the desired state } \\
\text { 5. Consider next steps for a future implementation site and how to close any gaps }\end{array}$ \\
\hline $\begin{array}{l}\text { Assess Information Technology } \\
\text { (IT) Systems }\end{array}$ & $\begin{array}{l}\text { I. Barcode scanners } \\
\text { - Assess technical compatibility with different styles of UDI barcodes } \\
\text { - Assess capability to communicate UDI data with the receiving POC IT system } \\
\text { 2. ERP, POC (inventory management), and clinical IT systems (clinical documentation/EHR) } \\
\text { - Define desired state based on UDI data exchange } \\
\text { - Determine UDI data transfer specifications among IT systems } \\
\text { - Assess and determine if upgrades, programming and/or new systems are needed to achieve the desired } \\
\text { state } \\
\text { 3. Interfaces } \\
\text { - Determine the interfaces needed to achieve the desired state } \\
\text { - Identify protocols, interfaces needed for exchange of UDI data among IT systems } \\
\text { - Enable UDI-based data exchange between the device database and POC IT systems } \\
\text { 4. Create the ability to store UDI in a designated field in IT systems and the EHR } \\
\text { 5. Work with IT team members and partners to achieve the desired state } \\
\text { 6. Consider next steps for a future implementation site, how to achieve the desired IT infrastructure and close } \\
\text { gaps, and which IT vendors and systems to work with }\end{array}$ \\
\hline Engage & $\begin{array}{l}\text { 1. Relationships } \\
\text { - Meet with impacted units and stakeholders to discuss purpose, benefits, and implementation of UDI } \\
\text { scanning } \\
\text { - Foster ongoing involvement of Leaders \& Champions } \\
\text { 2. Provide Education } \\
\text { 3. Maintain ongoing communication }\end{array}$ \\
\hline
\end{tabular}

(Continued) 
Table 3 (Continued).

\begin{tabular}{|c|c|}
\hline Key Step & Detailed Steps \\
\hline Review Status & $\begin{array}{l}\text { I. Ensure a functional, comprehensive device database that supports POC UDI capture, including daily updates } \\
\text { to the receiving POC IT system } \\
\text { 2. Ensure that scanners work } \\
\text { 3. Ensure the receiving POC IT system correctly receives the UDI barcode and forwards UDI data } \\
\text { 4. Ensure that staff have been educated and trained } \\
\text { 5. Ensure that support is in place for staff to know what and how to scan and whom to contact for problems } \\
\text { 6. Complete end-to-end testing and confirm data exchange among IT systems }\end{array}$ \\
\hline Go Live & $\begin{array}{l}\text { I. Maintain significant on-site presence during Go Live and for days thereafter } \\
\text { 2. Ensure long-term support is clear and easy to access for clinical staff doing barcode scanning, including } \\
\text { Education for new staff } \\
\text { 3. Listen, react, make changes as needed, continuing to utilize Expertise \& Support } \\
\text { 4. Be patient and positive } \\
\text { 5. Continue to foster Relationships } \\
\text { 6. Identify successes and learn from mistakes }\end{array}$ \\
\hline
\end{tabular}

Note: *Key Components are in bolded text.

Abbreviations: UDI, unique device identifier; POC, point of care; IT, information technology; ERP, enterprise resource planning; EHR, electronic health record.

Operational use was more extensive, including in contracting, purchasing, inventory management, charge capture, implant tracking, recalls, expiration date management, and outcomes analyses. Planned was UDI data utilization to inform clinical and operational decision-making, and data sharing for device evaluation and surveillance.

Outcomes information was limited. Shared was reduced clinician burden for documentation requirements, reduced transcription errors, recall efficiency, improved inventory accuracy, and greater data visibility. One interviewee stated:

"(UDI implementation) should help me take out a lot of ... extra data validation steps, cleansing or knowing that I'm talking apples to apples, whether it's in clinical comparative analysis or it's in supply chain inventory management.“

Anticipated outcomes with further UDI adoption included greater transparency of clinical patterns and variation, more information on device performance, enhanced expired and recalled device management, and greater staff satisfaction. As an interviewee stated: "Not enough UDI (is) out there yet to fully achieve value and use." Patient safety underpinned the focus on outcomes.

Metrics were underdeveloped. One interviewee shared that investigation of a signal such as central-line infections would be augmented with availability of UDIs.
Interviewees shared salient advice to others pursuing UDI implementation. "There are challenges. Sometimes the rock rolls back down, but what a joyful adventure it is trying to make things better." "(We are developing) an approach that outlasts time."

\section{Discussion}

A comprehensive UDI-enabled system embeds a standard for documentation, tracking, and identification of devices used in patient care, which is highly significant and important for patient safety. This allows greater ease of device identification and supports necessary steps prior to a revision procedure or other surgery, scheduling an MRI, in an emergency or in general patient care and maintenance of health and well-being. This additionally supports greater accuracy and efficiency of device identification in device recalls as well as advancing postmarket surveillance and studies to inform clinical decisionmaking. Despite FDA's regulatory achievement with the UDI Rule, ${ }^{1}$ the lack of adequate integration of UDIs into health system workflows and IT systems ${ }^{27}$ is a significant gap to achieve this goal. This project focused on this gap and utilized interviews of those experienced in UDI implementation to delineate an organized approach and help reduce complexity. To our knowledge, this is the first time that a conceptual model for UDI implementation and detailed recommendations based on experiences of multiple health systems have been developed. Although 
higher risk implantable devices were the focus in the interviews, the roadmap is considered generalizable for other device types. Acknowledged is that initial commitment to invest in UDI implementation may be influenced more by the higher risk implantable, life sustaining and life supporting devices.

Specific tenets of UDI implementation gleaned from this project warrant discussion. UDI implementation must be done across organizational silos in a hospital system, involving personnel who do not traditionally work together. Clinical champions, "buy-in" by clinical staff, and interdisciplinary relationships are central to success. The importance of champions to facilitate implementation efforts in health care is well supported in the literature. ${ }^{28-31}$ Supply chain management is the backbone of health system UDI implementation but will not be successful alone. Whereas participating organizations had diversity in their combinations of IT systems, their commonality was an infrastructure of interfaced IT systems, unified by using UDI. This was grounded in a functional and comprehensive database containing UDI-DI's, capability to scan and document the UDI in a POC IT system, and transfer these data. External entities, such as IT vendors and manufacturers, have significant influence in advancing needed infrastructure and addressing barriers. UDI use, metrics, and documentation of outcomes are underdeveloped. The latter is consistent with literature on the significant work required to lay the foundation before IT can support data visibility and analytics to inform performance. ${ }^{32}$ Work to address these areas continues by industry groups, ${ }^{16}$ through research, ${ }^{14,17,25,26}$ and is part of the necessary collective work to enhance public health and patient safety surrounding medical devices.

Ongoing UDI work continues to build the knowledge base and value proposition for UDI adoption. The BUILD Extension Project ${ }^{14}$ advanced understanding of the enabling role of UDI. UDI supported linkages of clinical and device data and was the standard across IT systems, workflows, processes, and documentation to enable the project's longitudinal analysis of coronary stent effectiveness and safety. The UDI2Claims Project, in anticipation of an updated insurance claims form in 2024 that includes a data field for the UDI-DIs of high-risk implantable devices, ${ }^{33}$ studied transmission of UDI-DI between health systems and payers. ${ }^{17,25}$ Whereas the software modifications for this transmission were not onerous, relationships and engagement across organizational units were more challenging. This is consistent with findings presented in the roadmap: coordination between different units was challenging - Foundational Themes: interprofessionalism, collaboration, communication and OR nurses perceived they had to modify their workflow and remember to scan UDIs of implants - Key Components: Relationships, Education. ${ }^{17}$ The National Evaluation System for Health Technology (NESTcc) is supporting a project to study UDI implementation and use in health system partners. ${ }^{34,35}$

To advance the findings of this study, the following recommendations for future research studies are provided:

1. Study a broader group of health systems, in both inpatient and outpatient settings, at varying stages of UDI implementation to assess readiness, facilitators, and barriers.

2. Perform workflow analysis of UDI integration in health systems.

3. Study the technical build in more detail and map the optimal IT infrastructure.

4. Assess UDI use cases and the impact of UDI use on clinical and operational outcome measures.

5. Test this roadmap in health systems.

6. Assess the financial aspects and cost/benefit of UDI implementation.

Additionally recommended is development of tools:

1. UDI education and training materials.

2. Metrics for UDI use.

Study Limitations: The team was unable to engage all recommended health systems in the project; however, a high percentage of those advanced enough to study participated. The team may not have received recommendation for all potential interviewees from a health system; however, 24 interviews were conducted in ten health systems. There was greater representation of health system UDI implementation in inpatient areas and those for cardiovascular procedures, so there may be limitations in full generalizability of findings. However, there was significant representation from inpatient settings such as the OR and IR and representation of outpatient settings as shown in Figure 1.

\section{Conclusion}

The critical next step to achieve a comprehensive UDIenabled system for patient safety is UDI adoption in health systems. UDIs need to be electronically documented when 
devices are used in patient care, so they are further available for use in patient care, device research, evaluation and surveillance, and to provide patients information on devices used in their care. Prioritization of this is way overdue. The UDI implementation roadmap can help close the gap and allow health systems to support improved device safety and effectiveness for patients.

\section{Acknowledgments}

This project would not have been possible without significant multi-stakeholder work and support. We thank the BUILD Consortium members for their engagement and support of the project: Dennis Black, Becton, Dickinson and Company; Kevin Capatch, M.S., Geisinger; Jeff Dressler, MBA, Abbott Laboratories; Curtis Dudley, Mercy; Jo Carol Hiatt, M.D. MBA, previously Kaiser Permanente; Theodore Heise, Ph.D., RAC, MED Institute; Kay Hysell, Mayo Clinic; Tom Maughan, DePuySynthes; Bart Phillips, M.S., Medtronic; Terrie Reed, M.S., previously US FDA; Angela Silvestri, RAC, Stryker; Cynthia Shumway, Intermountain Healthcare; Brad Steger, Zimmer Biomet; Paul Varosy, M.D., FACC, FAHA, FHRS, Department of Veterans Affairs Eastern Colorado Health Care System; Kirk Wiedmeier, previously Duke University Health System (Ended involvement before project end: Lesley Kelly Hall, previously Healthwise; Michael Schiller, CMRP, AHRMM). We thank Melina CoxFerreras, M.S. and Lara Salvo, M.S. for their project support. We thank Jennifer Ridgeway, $\mathrm{PhD}$ for her critical review and edit of this manuscript.

\section{Funding}

This work was supported by HHS-FDA 1U01FD00547601 as well as grants from Johnson \& Johnson and Medtronic, Inc. The funds were received by Mercy.

\section{Disclosure}

Natalia Wilson: Advisory Committees for AIM North America UDI Advisory Committee, Association for Health Care Resource \& Materials Management Learning UDI Community Steering Committee; Consulting for Arizona State University's Center for Healthcare Delivery and Policy, Mass General Brigham; Research funding from National Evaluation System for health Technology Coordinating Center (NESTcc), Patient-Centered Outcomes Research Institute; Purchased stock options in VitreosHealth. James Tcheng: On the Board of Directors of the Regenstrief Foundation, Member of the HL7 Advisory Council, Co-chair of the HL7 Clinical Interoperability Council, Consultant for Lumedx. Jove Graham: Research funding from AstraZeneca, Medtronic Inc., Purdue Pharma LP, Patient-Centered Outcomes Research Institute, Pfizer Inc. The authors report no other conflicts of interest in this work.

\section{References}

1. Food and Drug Administration, HHS. Unique device identification system. Federal Register. 2013;78:58785-58828. Codified at 21 CFR $16,801,803,806,810,814,820,821,822,830$.

2. U.S. Food and Drug Administration. UDI Basics; [updated May 14, 2019]. Available from: https://www.fda.gov/medical-devices/uniquedevice-identification-system-udi-system/udi-basics. Accessed July 9, 2021.

3. U.S. Food and Drug Administration. Unique device identification system (UDI System); [updated May 20, 2021]. Available from: https://www.fda. gov/medical-devices/device-advice-comprehensive-regulatory-assistance /unique-device-identification-system-udi-system. Accessed July 9, 2021.

4. U.S. Food and Drug Administration. Benefits of a UDI System; [updated September 27, 2018]. Available from: https://www.fda. gov/medical-devices/unique-device-identification-system-udi-system /benefits-udi-system. Accessed July 9, 2021.

5. US Food and Drug Administration. Medical device safety action plan; September 18, 2019. Available from: https://www.fda.gov/ media/112497/download. Accessed July 9, 2021.

6. Dhruva SS, Ross JS, Schulz WL, Krumholz HM. Fulfilling the promise of unique device identifiers. Ann Intern Med. 2018;169 (3):183-185. doi:10.7326/M18-0526

7. Aston JW, Howarth AL, Wilson NA, Mahabir RC. The value of unique identifiers in plastic surgery. Aesthet Surg J. 2018;38 (11):1264-1266. doi:10.1093/asj/sjy210

8. Wilson NA, Broatch J, Jehn M, Davis CM. National projections of time, cost and failure in Implantable device identification: consideration of unique device identification use. Healthc. 2015;3(4):196-201. doi:10.1016/j.hjdsi.2015.04.003

9. Wilson NA, Reich AJ, Graham J, Bhatt DL, Nguyen LL, Weissman JS. Patient perspectives on the need for implanted device information: implications for a post-procedural communication framework. Health Expect. 2021;1-12. doi:10.1111/hex.13273

10. Kinard M, McGiffert L. Medical device tracking - How it is and How it should be. JAMA Intern Med. 2021;181(3):305-306. doi:10.1001/jamainternmed.2020.7797

11. Drozda JP, Dudley C, Helmering P, Roach J, Hutchison L. The mercy unique device identifier demonstration project: implementing point of use product identification in the cardiac catheterization laboratories of a regional health system. Healthc. 2015;4(2):116-119. doi:10.1016/j. hjdsi.2015.07.002

12. The Plastic Surgery Foundation. National breast implant registry. Available from: https://www.thepsf.org/research/registries/nbir. Accessed July 9, 2021.

13. Levine BR, Springer BD, Golladap GJ. Highlights of the 2019 American joint replacement registry annual report. Arthroplast Today. 2020;6(4):998-1000. doi:10.1016/j.artd.2020.09.010

14. MDEpiNet. UDI adoption. Available from: https://www.mdepinet. net/build. Accessed July 9, 2021.

15. Drozda JP Jr, Roach J, Forsyth T, Helmering P, Dummitt B, Tcheng JE. Constructing the informatics and information technology foundations of a medical device evaluation system: a report from the FDA unique device identifier demonstration. $J$ Am Med Inform Assoc. 2018;25(2):111-120. doi:10.1093/jamia/ocx041

16. AHRMM. Learning UDI community. Available from: https://www. ahrmm.org/resources/learning-udi-community. Accessed July 9, 2021. 
17. Krupka DC, Graham J, Wilson N, et al. Transmitting device identifiers of implants from the point of care to insurance claims: a demonstration project. $J$ Patient Saf. 2021;17(3):223-230. doi:10.1097/PTS.0000000000000828

18. Engelberg Center for Health Care Reform. The Brookings institution. Unique Device Identifiers (UDIs): a roadmap for effective implementation; December, 2014. Available from: https://www.brook ings.edu/wp-content/uploads/2016/06/UDI-Final-12052014-1.pdf. Accessed November 11, 2021

19. Campion TR, Johnson SB, Paxton EW, Mushlin AI, Sedrakyan A. Implementing unique device identification in electronic health record Systems. organizational, workflow, and technological challenges. Med Care. 2014;52(1):26-31. doi:10.1097/MLR.0000000000000012

20. The Pew Charitable Trusts. Implementing unique device identification. recommendations for integrating medical device data throughout the health care system; September, 2015. Available from: https:// www.pewtrusts.org/-/media/assets/2015/09/udiimplementationreport.pdf. Accessed November 11, 2021.

21. BUILD consortium member biographies. Available from: http://mde pinet.org/wp-content/uploads/June-2019-BUILD-ConsortiumMember-Biographies-2-1.pdf. Accessed July 9, 2021.

22. Ritchie J, Spencer L. Qualitative data analysis for applied policy research. In: Huberman AM, editor. The Qualitative Researcher's Companion. Thousands Oaks: Sage; 2002:305-329.

23. Srivastava A, Thomson SB. Framework analysis: a qualitative methodology for applied policy research. JOAAG. 2009;4(2):72-79.

24. Gale NK, Heath G, Cameron E, Rashid S, Redwood S, Using the framework method for the analysis of qualitative data in multi-disciplinary health research. BMC Med Res Methodol. 2013;13(1):117. doi:10.1186/1471-2288-13-117

25. Zerhouni YA, Krupka DC, Graham J, et al. UDI2Claims: planning a pilot project to transmit identifiers for implanted devices to the insurance claim. [published online ahead of print, 2018 Nov 21]. J Patient Saf. 2018. doi:10.1097/PTS.0000000000000543
26. Krupka DC, Wilson NA, Reich AJ, Weissman JS. The post-market surveillance system for implanted devices is broken. Here's How CMS and The FDA can act now to fix it. Health Aff Blog. 2021. doi:10.1377/hblog20210420.717948

27. Darrow JJ, Avorn J, Kesselheim AS. FDA regulation and approval of medical devices: 1976-2020.JAMA.2021;326(5):420-432. doi:10.1001/ jama.2021.11171

28. Miech EJ, Rattray NA, Flanagan ME, Damschroder L, Schmid AA, Damush TM. Inside help: an integrative review of champions in healthcare-related implementation. SAGE Open Med. 2018;6:1-11. doi:10.1177/2050312118773261

29. Penney LS, Moreau JL, Miake-Lye I, et al. Spreading the Veterans health administration's emergency department rapid access clinics (ED-RAC) innovation: role of champions and local contexts. Healthc. 2021;9(2):100515. doi:10.1016/j.hjdsi.2020.100516

30. Flanagan ME, Plue L, Miller KK, et al. A qualitative study of clinical champions in context: clinical champions across three levels of acute care. SAGE Open Med. 2018;6:108. doi:10.1177/ 2050312118792426

31. Bonawitz K, Wetmore M, Heisler M, et al. Champions in context: which attributes matter for change efforts in healthcare? Implement Sci. 2020;15(1):62. doi:10.1186/s13012-020-01024-9

32. Rudin RS, Fischer SH, Damberg CL, et al. Optimizing health IT to improve health system performance: a work in progress. Healthc. 2020;8(4):100483. doi:10.1016/j.hjdsi.2020.100483

33. X12. X12 standards for electronic data interchange technical report type 3 - Health care claim: institutional (837); 2019.

34. NEST Coordinating Center. Emerging issues in UDI: a NEST collaborative community discussion. Available from: https://nestcc.org/ events/emerging-issues-in-udi-a-nest-collaborative-communitydiscussion/. Accessed July 9, 2021.

35. NEST Coordinating Center. UDI Center. Available from: https:// nestcc.org/udi-center/. Accessed November 17, 2021
Medical Devices: Evidence and Research

\section{Publish your work in this journal}

Medical Devices: Evidence and Research is an international, peerreviewed, open access journal that focuses on the evidence, technology, research, and expert opinion supporting the use and application of medical devices in the diagnosis, monitoring, treatment and management of clinical conditions and physiological processes. The identification of novel devices and optimal use of existing devices which will lead to improved clinical outcomes and more effective patient management and safety is a key feature of the journal. The manuscript management system is completely online and includes a very quick and fair peer-review system. Visit http:// www.dovepress.com/testimonials.php to read real quotes from published authors. 